\title{
Engineering Behavior of Modified Warm Mix Asphalt Mixtures
}

\author{
Sebaaly P E* and Hand A J \\ Department of Civil \& Environmental, University of Nevada, USA
}

Submission: January 23, 2018; Published: March 27, 2018

*Corresponding author: Sebaaly P E, University of Nevada, Reno, NV 89557, United States, Tel: +1-775-784-6565; Fax: +1-775-784-1429;

Email: psebaaly@unr.edu

\begin{abstract}
The past few years have seen the introduction of the warm mix asphalt (WMA) technology in efforts to reduce the required energy for the production and construction of the asphalt concrete layer. The basic principle of the WMA technology is to lower the mixing and compaction temperatures of the produced mixture through lowering the viscosity-temperature relationship of the asphalt binder.
\end{abstract}

This paper evaluates the performance of polymer and tire rubber modified binder in WMA mixtures manufactured with two WMA technologies; Advera and Sasobit. The evaluation consisted of assessing the engineering behavior of mixtures with and without moisture damage. The resistance of the mixtures to moisture damage was evaluated in terms of the impact of multiple freeze-thaw cycling on the dynamic modulus property and engineering behavior of the mixtures was evaluated in terms of their resistance to rutting and fatigue cracking.

The paper presents the results of the study showing the performance of polymer and tire rubber modified binder in WMA mixtures as compared to WMA manufactured with neat binders. The use of polymer and tire rubber modified binder with WMA mixtures significantly improves their resistance to moisture damage, rutting, and fatigue cracking. Among all mixture evaluated in this study, the best performance was obtained from the polymer and tire rubber modified mixtures treated with hydrated lime. This observation was true for control, WMA-Advera, and WMA-Sasobit mixtures.

Keywords: Tire rubber; Warm mix asphalt; Moisture damage; Dynamic modulus; Rutting; Fatigue cracking

Abbreviations : WMA : Warm Mix Asphalt; HMA: Hot Mix Asphalt; NCAT: National Center for Asphalt Technology; TR: Tire Rubber; TS: Tensile Strength; TSR: Tensile Strength Ratio; MEPDG: Mechanistic-Empirical Pavement Design Guide; LVDT: Linear Variable Differential Transformers

\section{Introduction}

Warm mix asphalt (WMA) additives allow reductions in the temperatures at which asphalt mixtures are produced and placed are becoming popular for their potential impact on the performance of asphalt pavements. The immediate benefit of producing WMA mixtures is the reduction in the consumption of energy required to produce the traditional hot mix asphalt (HMA). WMA additives also improve workability and compactability of mixtures to a point where they can be produced at lower temperatures. With the decreased production temperatures comes the benefit of reduced emissions, fumes, dust production and odors, as well as an extended mix haul distance.

In 2005, The National Center for Asphalt Technology (NCAT) conducted a study to evaluate the impact of the lower mixing temperature of WMA mixture, with two objectives:

a. Evaluate the impact of residual moisture in aggregates and b. Evaluate the impact of lower asphalt binder aging. The NCAT study evaluated two WMA additives (Sasobit and Advera) mixed with two asphalt binders (PG64-22 and PG58-28) and two aggregate sources. The tensile strength ratio defined as the ratio of the moisture-damaged tensile strength over the undamaged tensile was used as an indicator of the WMA mixtures resistance to moisture damage. The NCAT study concluded that the two WMA additives, when coupled with residual aggregate moisture and lower binder aging, reduced the tensile strength properties of the WMA mixtures which may contribute to their lower resistance to moisture damage in the field.

A research study conducted at the University of Nevada concluded that the amount of residual moisture in the aggregates is directly related to the mixing temperature of the WMA mixture leading to residual moistures between 015 to 0.77 percent by weight of aggregate [1]. The study evaluated 


\section{Civil Engineering Research Journal}

the engineering property, defined as the dynamic modulus, after 1 and 6 freeze-thaw cycles of WMA mixtures with and without residual moisture. Based on the data generated from this study, it was concluded that residual moisture has a significant impact on the engineering properties of WMA mixtures manufactured with Sasobit and Advera. Therefore, future evaluations of WMA mixtures must incorporate the impact of residual moisture in the aggregates caused by the lower mixing temperature of the WMA mixture.

\section{Scope}

The intention of this research effort was to evaluate the use of polymer (PM) and tire rubber modified (TR) binders with WMA mixtures and to compare its performance with WMA mixtures made with neat binders. The research evaluated the resistance of WMA mixtures to moisture damage and their resistance to rutting and fatigue cracking.

It should be clearly noted that the tire rubber modified binder is different than the crumb rubber-modified (CRM) binder in that the TR binder is blended at the terminal and shipped to the asphalt plant ready to be used while the CRM binder is typically blended and cured at the asphalt plant prior to mixing which requires additional equipment at the plant. However, both the TR and CRM binders are modified with tire rubber. This research only evaluated WMA and control asphalt mixtures made with the TR binder.

\section{Materials and Methods}

The asphalt binders used in this research consisted of a polymer-modified PG64-28PM tire rubber-modified PG6428TR, and a neat PG64-22. The aggregate came from an andesitic basalt quarry in northern Nevada, USA that supplies asphalt aggregates to Nevada and California. In order to assess the relative performance of WMA mixtures, base line mixtures were also evaluated using the same asphalt binders and aggregates but manufactured at the temperature of hot mix asphalt (HMA) mixtures.

Two anti-strip additives were evaluated in this research effort for mitigating potential moisture damage: hydrated lime and liquid anti-strip. The standard method of adding hydrated to aggregates used in Nevada and California was followed whereby dry lime at the rate of $1 \%$ by weight of aggregate was added to the mix. The liquid additive was blended in the binder at a rate of $0.5 \%$ by weight of binder.

The National Cooperative Highway Research Program (NCHRP) project 9-43 recommended the use aggregate coating, and compactability criteria to determine the mixing and compaction temperatures for the various WMA mixtures [2]. These procedures were followed in this research and the results are shown in Figure 1. In general, the WMA additives reduced the mixing and compaction temperature of the neat mixtures by $25-30{ }^{\circ} \mathrm{C}$ while they only reduced the mixing and compaction temperatures of the modified mixtures by $17-25^{\circ} \mathrm{C}$.

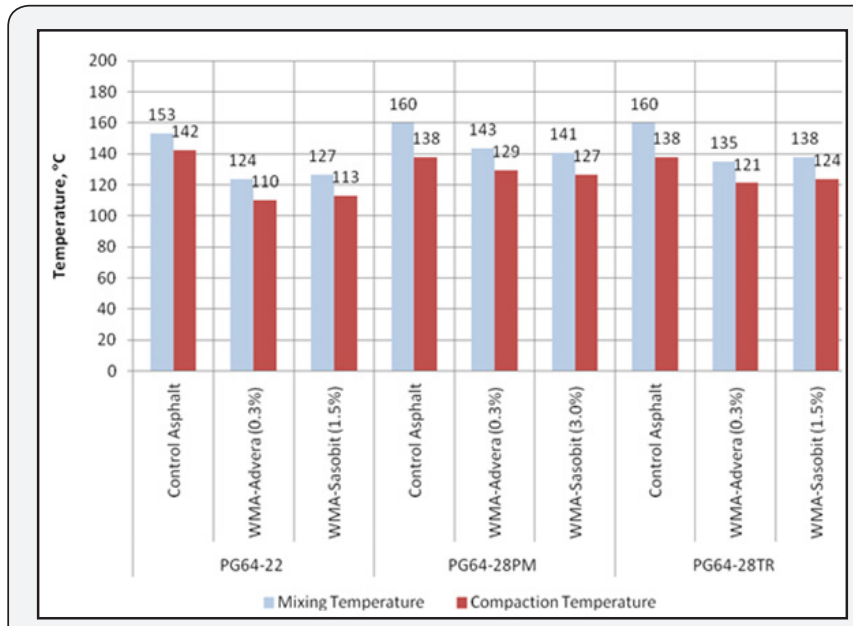

Figure 1: Mixing and compaction temperatures for various mixtures.

The optimum binder contents that were obtained for the control asphalt mixtures were verified for WMA mixtures using the procedures discussed above. Table 1 summarizes the mix design information for the control asphalt and WMA mixtures. For each binder type, the optimum binder contents are similar for control mixtures and WMA mixtures and for both types of anti-strip additive.

Table 1: Summary of mix designs.

\begin{tabular}{|c|c|c|c|c|}
\hline \multirow[t]{2}{*}{ Mix Type } & \multirow[t]{2}{*}{ Treatment } & \multicolumn{3}{|c|}{$\begin{array}{l}\text { Optimum Binder Content, } \\
\text { percent dry weight of } \\
\text { aggregate }(\%)\end{array}$} \\
\hline & & PG64-22 & $\begin{array}{l}\text { PG64- } \\
\text { 28PM }\end{array}$ & $\begin{array}{c}\text { PG64- } \\
\text { 28TR }\end{array}$ \\
\hline \multirow{3}{*}{$\begin{array}{l}\text { Control } \\
\text { Asphalt }\end{array}$} & Un-treated & 5.7 & 5.8 & 5.7 \\
\hline & Lime-treated & 5.6 & 5.6 & 5.6 \\
\hline & Liquid-treated & 5.7 & 5.8 & 5.7 \\
\hline \multirow{3}{*}{$\begin{array}{l}\text { WMA- } \\
\text { Advera }\end{array}$} & Un-treated & 5.7 & 5.8 & 5.7 \\
\hline & Lime-treated & 5.6 & 5.6 & 5.6 \\
\hline & Liquid-treated & 5.7 & 5.8 & 5.7 \\
\hline \multirow{3}{*}{$\begin{array}{c}\text { WMA } \\
\text {-Sasobit }\end{array}$} & Un-treated & 5.7 & 5.8 & 5.7 \\
\hline & Lime-treated & 5.6 & 5.6 & 5.6 \\
\hline & Liquid-treated & 5.7 & 5.8 & 5.7 \\
\hline
\end{tabular}

\section{Laboratory Testing Methods}

The laboratory experimental program evaluated the moisture resistance of the mixtures using their engineering properties and their performance characteristics in terms of resistance to permanent deformation and fatigue cracking. This section briefly describes the actual laboratory testing methods while the next section presents the analyses of the data generated form the experiment.

\section{Freeze-thaw cycles}

Freeze-thaw cycling was used to simulate the impact of short and long-term moisture damage on control mixtures and WMA mixtures. Each F-T cycle consisted of the following steps: 


\section{Civil Engineering Research Journal}

i. Induce 70-80 percent saturation into the compacted samples

ii. Subject the saturated samples $-18^{\circ} \mathrm{C}$ for 16 hours

iii. Place the frozen sample in over at $60^{\circ} \mathrm{C}$ for 24 hours

iv. Repeat steps 2 and 3 to achieve the desired number of F-T cycles

\section{Tensile strength}

The impact of moisture on the tensile strength (TS) property of the asphalt mixture has been widely used to assess its to moisture damage. The TS is measured as the maximum tensile stress (i.e., calculated from the maximum load) at the center of the compacted sample when loaded in compression along its diametrical direction. The loading rate of the TS test is $50 \mathrm{~mm} /$ min. The values of TS and tensile strength ratio (TSR) have been typically used to assess the short-term moisture damage of asphalts.

\section{Dynamic Modulus}

The AASHTO Mechanistic-Empirical Pavement Design Guide (MEPDG) uses the dynamic modulus (E*) master curve to evaluate the structural response of the flexible pavement under various combinations of traffic loads, speed, and environmental conditions [3]. The $\mathrm{E}^{*}$ test consists of testing $100 \mathrm{~mm} \times 150 \mathrm{~mm}$ cylindrical sample under uniaxial state of stress. Under zero confining pressure, a sinusoidal deviator stress is applied. The sinusoidal axial deformation is measured over the middle $100 \mathrm{~mm}$ of the sample by two linear variable differential transformers (LVDTs) placed 180 degrees apart. The sinusoidal strain is calculated as the ratio of the deformation over the $100 \mathrm{~mm}$ gauge length times 100 . The amplitude of the $\mathrm{E}^{*}$ is calculated as the ratio of the maximum sinusoidal stress over the maximum sinusoidal strain. The $\mathrm{E}^{*}$ property of the various mixtures is measured under multiple combinations of loading frequency of $25,10,5,0.5,0.1 \mathrm{~Hz}$ and temperature of $4,21,38$, and $55^{\circ} \mathrm{C}$ as specified by AASHTO T378 [4]. Using the viscoelastic behavior of asphalt mixtures (i.e. interchangeability of the effect of loading rate and temperature) the master curve is developed as specified by AASHTO R84 [4]. The master curve can be used to identify the appropriate $\mathrm{E}^{*}$ for any combination of pavement temperature and traffic speed. The $\mathrm{E}^{*}$ property provides an indication of the general quality of asphalt mixtures. The relationship between $\mathrm{E}^{*}$ and the number of F-T cycles gives an excellent indication of the resistance of a mixture to long-term moisture damage.

\section{Flow Number}

The resistance of various mixtures to rutting was evaluated by measuring the flow number (FN) for each mixture following AASHTO T378 [4]. A $100 \times 150 \mathrm{~mm}$ sample with $7.0 \pm 0.5 \%$ air voids were tested at $58{ }^{\circ} \mathrm{C}$ under repeated haversine axial compressive load pulse of $0.1 \mathrm{~s}$ followed by $0.9 \mathrm{~s}$ rest period without confinement. The resulting permanent axial strains were measured as a function of the load cycles and numerically differentiated to calculate the FN per AASHTO R84. The FN is defined as the number of load cycle at which the asphalt mixture exhibits tertiary flow. The main concern with WMA mixtures is that the lower mixing temperature will not provide sufficient stiffness during the early life of the asphalt pavement which will lead to early failure in rutting.

\section{Flexural Beam Fatigue}

The resistance of the un-treated asphalt mixtures to fatigue cracking was evaluated using the flexural beam fatigue test according to AASHTO T321 [4]. A $64 \times 50 \times 380 \mathrm{~mm}$ beam specimen is subjected to a 4-point bending with free rotation and horizontal translation at all load and reaction points. This produces a constant bending moment over the center portion of the specimen. Constant strain tests were conducted at three different strain levels, using a repeated harversine load at a frequency of $10 \mathrm{~Hz}$. Initial flexural stiffness was measured at the $50^{\text {th }}$ load cycle. Fatigue life or failure is defined as the number of cycles corresponding to a $50 \%$ reduction in the initial stiffness.

\section{Analysis of Mixtures Properties}

\section{Resistance to moisture damage}

The resistances of the various mixtures to moisture damage were evaluated at the short-term and long-term stages. The un-conditioned and conditioned (i.e. after 1 F-T cycle) TS were used to evaluate the short-term moisture damage. The TSR was determined as the ratio of the TS after $1 \mathrm{~F}-\mathrm{T}$ cycle over the unconditioned TS times 100 . The unconditioned $\mathrm{E}^{*}$ and $\mathrm{E}^{*}$ after 6 F-T cycles were used to evaluate long-term moisture damage.

Figure 2-4 summarizes the short-term moisture damage of the various mixtures. The numbers over the bars represent the average values while the whiskers represent the range of measurements. The data in Figure 2 show that only the PM and TR control and Sasobit WMA mixtures pass the Superpave criteria of minimum TSR of 80 percent without additive. The data in Figures 3 show that the addition of lime significantly improved the TSR for all mixtures well above the Superpave criteria. The data in Figure 4 show that the addition of liquid anti-strip moderately improved the TSR for all mixtures with the PG64-22 Advera WMA TSR remained below the Superpave criteria.

Figures 5-7 shows the long-term moisture damage in terms of the un-conditioned $\mathrm{E}^{*}$ (i.e. 0 F-T cycles) and $\mathrm{E}^{*}$ after 6 F-T cycles for all mixtures. The ECR was determined as the ratio of the $\mathrm{E}^{*}$ after $6 \mathrm{~F}-\mathrm{T}$ cycle to the un-conditioned $\mathrm{E}^{*}$ times 100. Overall, the data show that $\mathrm{E}^{*}$ decreases as the mixtures are subjected to 6 F-T cycles. Based on the test results, the following trends were observed:

- $\quad$ The neat PG64-22 control and WMA mixtures showed the highest un-conditioned $\mathrm{E}^{*}$ property with significant reductions in $\mathrm{E}^{*}$ after $6 \mathrm{~F}-\mathrm{T}$ cycles. 


\section{Civil Engineering Research Journal}

- The un-treated Advera WMA mixtures experienced the largest reduction in $\mathrm{E}^{*}$ after 6 F-T cycles.

- $\quad$ The un-treated Sasobit WMA mixtures experienced moderate reduction in $\mathrm{E}^{*}$ after $6 \mathrm{~F}-\mathrm{T}$ cycles.

- The lime additive significantly improved the longterm resistance to moisture damage of all control and WMA mixtures. Previous research studies have shown that lime also improves the strength and performance characteristics of asphalt mixtures [5].

- $\quad$ The liquid additive moderately improved the long-term resistance to moisture damage of control and WMA mixtures except for the PG64-28TR Advera WMA mix which did not experience any improvement (Figure 7 shows the ECR curve for the liquid-treated Advera WMA mix overlapping the untreated curve) of PG64-28TR mixtures.

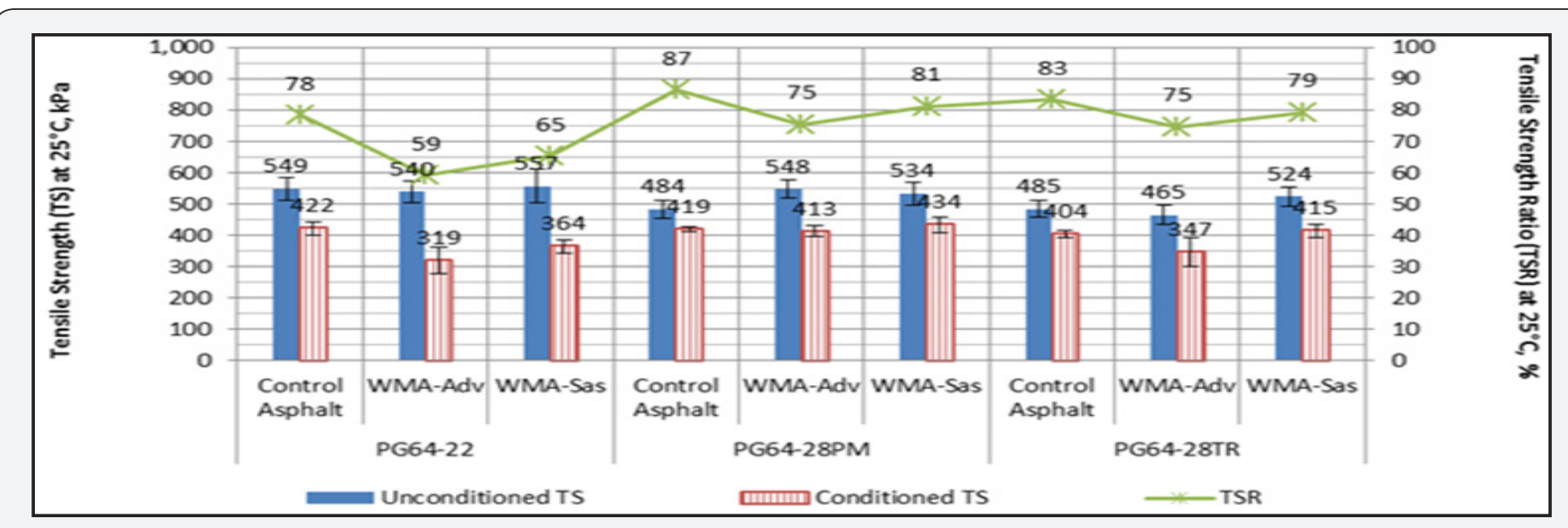

Figure 2 : Tensile strength properties of the un-treated mixtures.

\begin{tabular}{|c|c|c|c|c|c|c|c|c|c|c|c|c|}
\hline \multirow{10}{*}{ 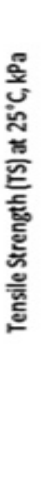 } & 1,000 & 90 & 85 & 86 & 91 & & 92 & 87 & 88 & 90 & 100 & $\overrightarrow{0}$ \\
\hline & $\begin{array}{l}900 \\
800\end{array}$ & & 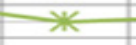 & & & 舟 & & & & & $\begin{array}{l}90 \\
80\end{array}$ & 릉 \\
\hline & 700 & & & 594 & & & & & & & 70 & ॐ \\
\hline & 600 & 561 & 535 & $I_{513}$ & 488 & 499 & 52582 & 483 & & & 60 & 丞 \\
\hline & $\begin{array}{l}500 \\
400\end{array}$ & & & & & $=I_{413}$ & & It: & $\begin{array}{l}455 \\
\text { 4501 } \\
\text { I901 }\end{array}$ & & so & 忍 \\
\hline & 300 & & & & & 50 & 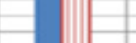 & & & & $\begin{array}{l}40 \\
30\end{array}$ & 을 \\
\hline & 200 & & & & & & & & & 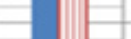 & 20 & $\approx$ \\
\hline & 100 & & & & & & & & 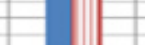 & 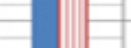 & 10 & స్తి \\
\hline & & $\begin{array}{l}\text { Control } \\
\text { Asphalt }\end{array}$ & WMA-Adv & WMA-Sas & $\begin{array}{l}\text { Control } \\
\text { Asphalt }\end{array}$ & WMA-Adv & WMA-Sas & $\begin{array}{l}\text { Control } \\
\text { Asphalt }\end{array}$ & WMA-Adv & WMA-Sas & & \\
\hline & & & PG64-22 & & & PG64-28PM & & & PG64-28TR & & & \\
\hline & & 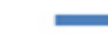 & = Unconditi & oned TS & & minm Cond & ditioned TS & & 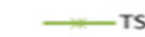 & & & \\
\hline
\end{tabular}

Figure 3 : Tensile strength properties of the lime-treated mixtures.

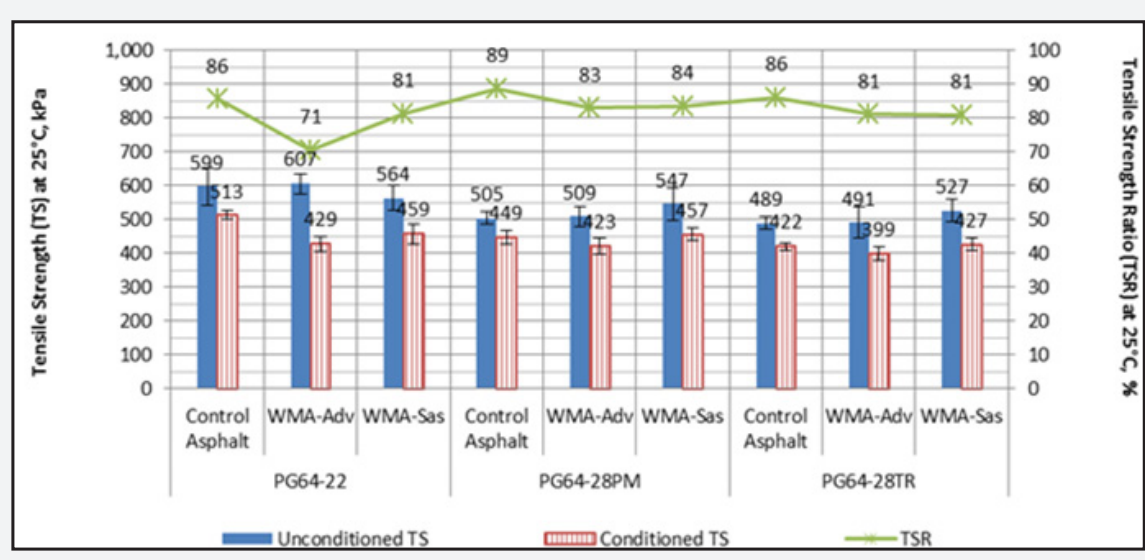

Figure 4 : Tensile strength properties of the liquid-treated mixtures. 


\section{Civil Engineering Research Journal}

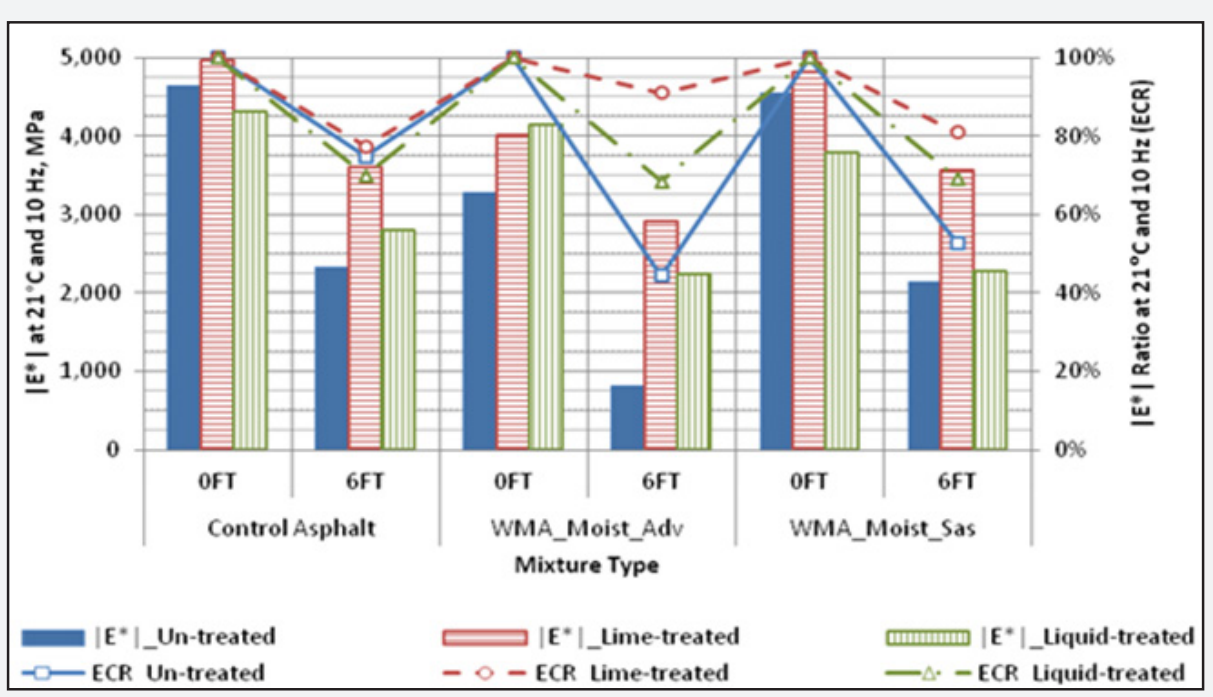

Figure 5 : Impact of long-term moisture damage on the dynamic modulus of PG64-22 mixtures.

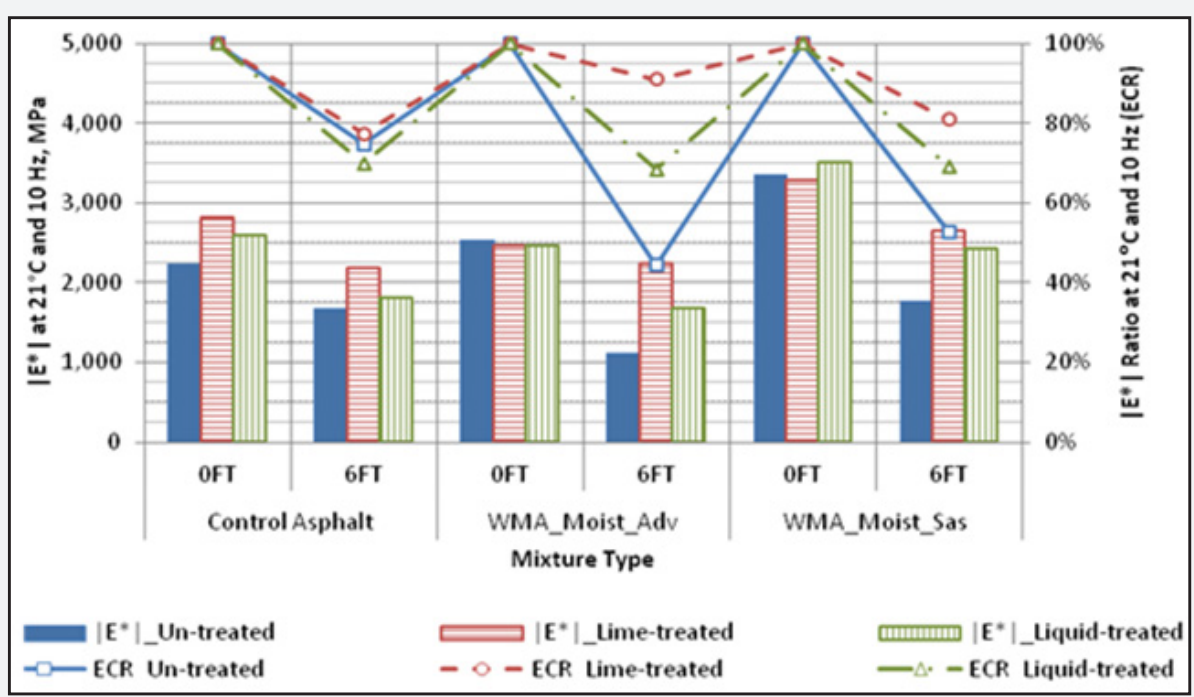

Figure 6 : Impact of long-term moisture damage on the dynamic modulus of PG64-28PM mixtures.

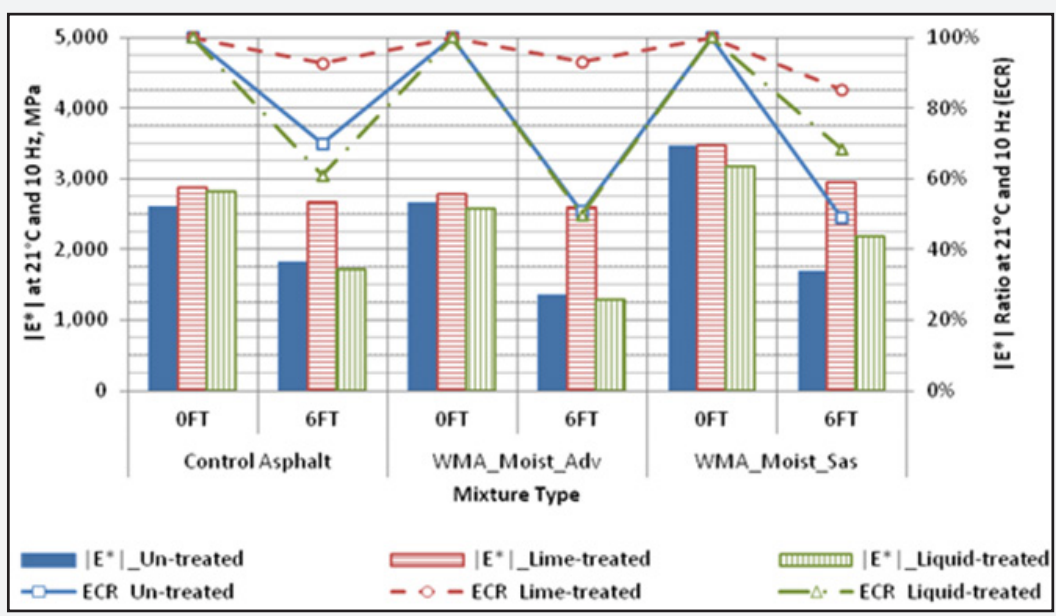

Figure 7 : Impact of long-term moisture damage on the dynamic modulus of PG64-28TR mixtures. 


\section{Civil Engineering Research Journal}

\section{Resistance to permanent deformation}

Figure 8 presents the flow number property of the various mixtures. The higher the FN, the more resistant the asphalt mixture is to permanent deformation. Based on the FN results, the following observations were made:

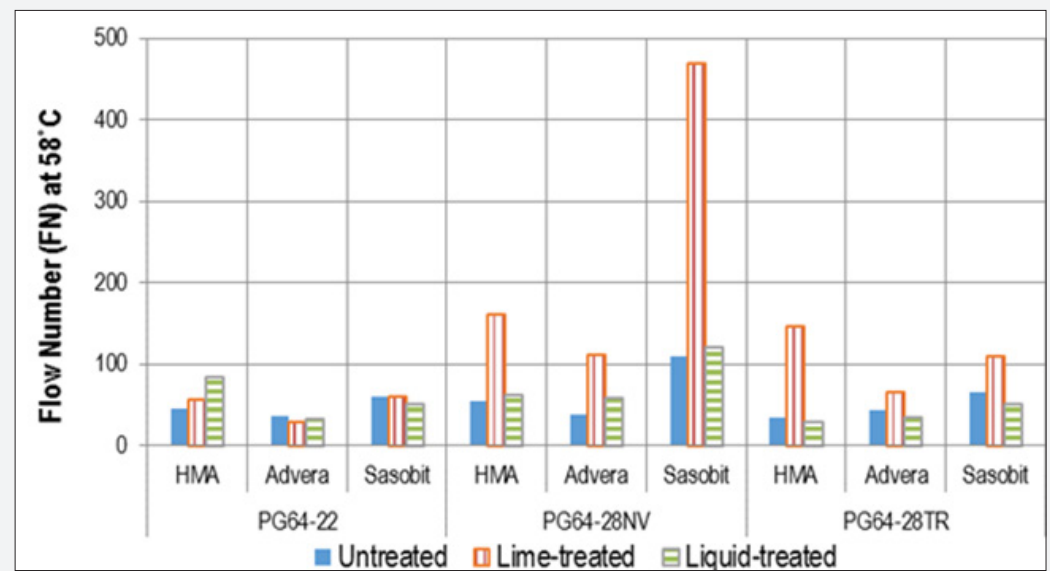

Figure 8 : Flow number results for all evaluated mixtures.

\section{PG64-22 mixtures:}

- $\quad$ The untreated Sasobit mixture had higher FN compared to the corresponding HMA mixture. However, lime and liquid treated Sasobit mixtures exhibited lower FN than their corresponding HMA mixtures.

- $\quad$ Advera mixture exhibited the lowest FN.

- The addition of lime increased the FN for the HMA mixtures while no significant improvement was observed when lime was added to WMA mixtures.

\section{PG64-28NV/PM mixtures:}

- $\quad$ Sasobit mixtures had the highest FN values followed by HMA then Advera mixtures.

- $\quad$ The addition of the lime significantly improved the FN measurements for both WMA and HMA mixtures. While the liquid anti-strip had less effect on increasing the FN of all mixtures.

\section{PG64-28TR mixtures:}

- $\quad$ Both Advera and Sasobit untreated and liquid-treated mixtures showed higher FN compared to their corresponding HMA mixtures.

- $\quad$ lime-treated Advera mixture showed an increase in the FN compared to the untreated and liquid-treated Advera mixtures;

- $\quad$ Untreated and liquid-treated Sasobit mixtures had a higher FN compared to their corresponding HMA and Advera mixtures;

- $\quad$ Lime-treated mixtures had the highest FN compared to untreated and liquid treated mixtures.
Overall, the Sasobit mixtures had the highest FN values compared to HMA and Advera mixtures. Moreover, polymer modified mixtures exhibited higher FN than the tire rubber modified mixtures. The addition of lime to all the mixtures improved their FN especially in the case of mixtures with polymer modification which showed a significantly high FN. The liquid anti-strip had a minor effect on the FN, and in some cases it decreased the FN of some mixtures [6].

\section{Resistance to fatigue cracking}

Figure 9 presents the measured fatigue curves of the different mixtures. The higher the fatigue curve the better the resistance of the mixture to fatigue cracking. Based on the presented data, the following observations were drawn:

PG64-22 mixtures: The Sasobit mixture exhibited the highest resistance to fatigue cracking among HMA and WMA mixtures at strain levels higher than 500 microstrain. However, HMA mixture had the highest fatigue resistance compared to WMA mixtures at lower strain levels.

PG64-28PM mixtures:

- Similar to the unmodified asphalt mixtures, the Sasobit mixture exhibited the highest resistance to fatigue cracking among HMA and WMA mixtures at strain levels higher than 700 microstrain. However, the HMA mixture had the highest fatigue resistance compared to WMA mixtures at lower strain levels.

- $\quad$ The Advera mixture exhibited, in general, similar trend as Sasobit, however, its resistance to fatigue cracking at low strain levels was the lowest among all mixtures.

PG64-28TR mixtures: The Advera mixture had a very similar behavior compared to the to the HMA mixture while the Sasobit mixture exhibited a lower resistance to fatigue cracking compared to all other mixtures especially at lower strain levels. 


\section{Civil Engineering Research Journal}

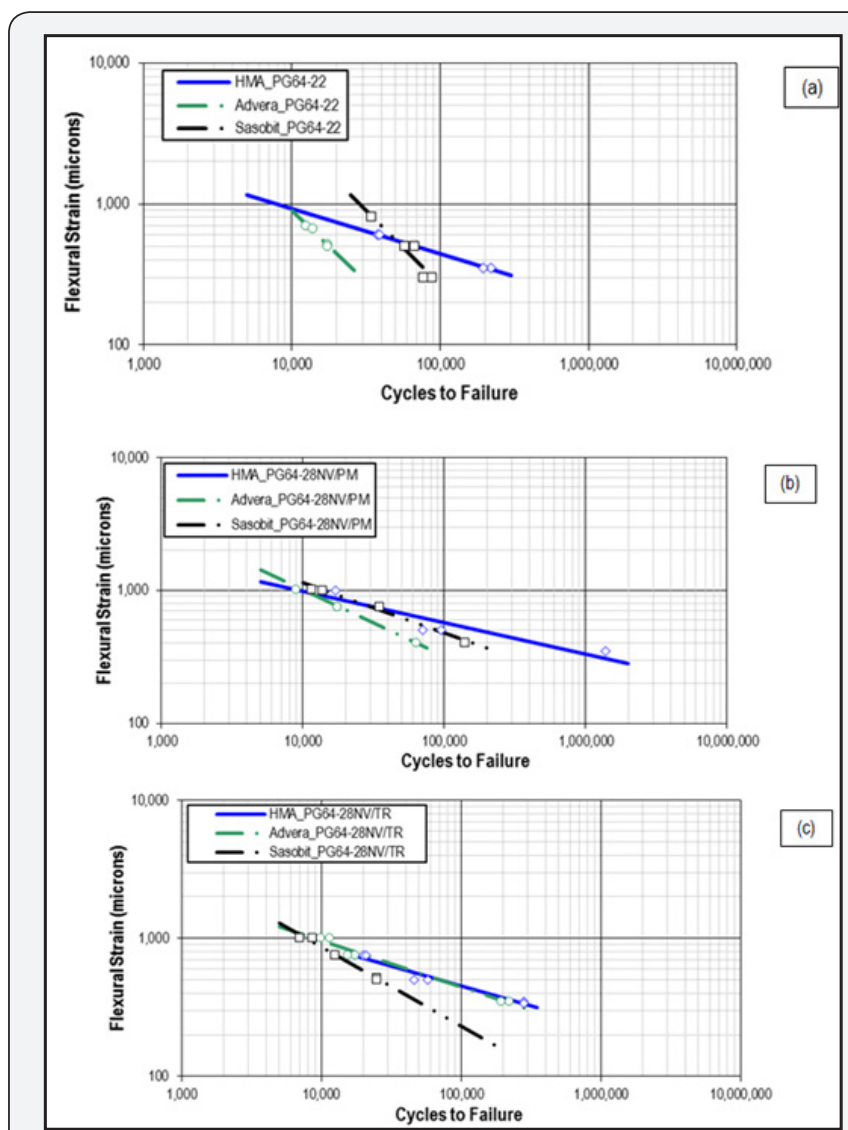

Figure 9: Fatigue cracking resistance for evaluated mixtures.

When the three asphalt binders are compared, the polymer modified binder seemed to significantly improve the fatigue resistance while the tire rubber modified asphalt binder had a minimal fatigue resistance improvement over the unmodified binder. The Sasobit WMA technology when combined with both unmodified and polymer modified binders showed a good resistance to fatigue cracking, whereas Advera was more effective when it was combined with the tire rubber modified binder. Overall, the HMA mixtures had a better fatigue resistance than WMA mixtures except for the Sasobit with unmodified mixture at high strain levels.

Since WMA mixtures were subjected to a lower curing time and temperature for the short time aging, it was expected that they will show a better resistance to fatigue cracking. However, that was not the observed results. It is believed that the long term aging process might mask the short term aging procedure and that the resistance to fatigue cracking is more impacted by the type of the WMA additive than by the lower WMA mixing temperatures.

Also it was observed that mixtures with tire rubber binder showed a close behavior between the HMA and WMA mixtures, while the PG64-22 and PG64-28PM mixtures had showed a difference between the HMA and WMA, so it can be concluded that for fatigue resistance the binder type plays the most important role and it will dictate the behavior of a mixture, as well the impact of the WMA additives.

\section{Conclusion and Recommendations}

The laboratory research effort documented in this study investigated the impact of WMA additives on the performance of polymer and tire rubber modified asphalt mixtures with and without WMA additives. Based on the experimental test results the following conclusions can be made:

- Mixtures with polymer or rubber modified binders have shown the best moisture resistance. An exclusive comparison among WMA additives revealed that Sasobit mixtures exhibited better resistance to moisture damage than the Advera mixtures.

- A significant improvement was observed in the moisture resistance when lime was added to all mixtures, while liquid anti-strip additive showed a minimal improvement compared to untreated mixtures. Furthermore, lime treated Sasobit mixtures with modified binders had the highest resistance to moisture damaged followed by HMA and Advera mixtures, respectively.

- Lime treated mixtures with modified asphalt binders exhibited the highest resistance to permanent deformation compared to untreated mixtures while a minimal improvement was observed with liquid anti-strip treatment. The combination between polymer modified asphalt binders with Sasobit WMA additive can lead to a superior mixture in resisting permanent deformation.

- Polymer modified HMA mixtures exhibited the best resistance to fatigue cracking among all evaluated mixtures followed by the tire rubber modified HMA mixtures. Among WMA mixtures, Sasobit exhibited higher fatigue life than Advera mixtures. Moreover, polymer and rubber modifications had the highest impact on improving the fatigue resistance of WMA mixtures.

- In summary, by identifying an optimum binder type, binder content, anti-strip additive type, along with the WMA additive, a sustainable asphalt pavement can be designed to efficiently resist the moisture damage, rutting, and fatigue cracking.

\section{References}

1. Wong C (2011) Evaluation of Warm Mix Additives for Use in Modified Asphalt Mixtures: Phase I. Master Thesis. Department of Civil \& Environmental Engineering, University of Nevada, Reno.

2. National Cooperative Highway Research Program Project 9-43 (2008) Mix Design Practices for Warm Mix Asphalt. Transportation Research Board, National Research Council, Washington DC, USA.

3. National Cooperative Highway Research Program Project 1-37A (2004) Guide for Mechanistic-Empirical Design of New and Rehabilitated Structures. Transportation Research Board, National Research Council, Washington, DC, USA. 


\section{Civil Engineering Research Journal}

4. American Association of State Highway and Transportation Officials (2016) Standard Specifications of Transportation Materials and Methods of Sampling and Testing. 29 $9^{\text {th }}$ edition [CD-ROM].

5. Sebaaly PE, Hajj E, Little D, Shivakolunthar S, Sathanathan T, Vasconcelos K (2010) Evaluating the Impact of Lime on Pavement Performance. National Lime Association, Washington, DC, USA.
6. Hurley GC, Prowell BD (2006) Evaluation of Potential Processes for Use in Warm Mix Asphalt Mixes. Journal of the Association of Asphalt Paving Technologists, Vol 75.
This work is licensed under Creative Commons Attribution 4.0 License DOI: 10.19080/CERJ.2018.04.555633

\section{Your next submission with Juniper Publishers} will reach you the below assets

- Quality Editorial service

- Swift Peer Review

- Reprints availability

- E-prints Service

- Manuscript Podcast for convenient understanding

- Global attainment for your research

- Manuscript accessibility in different formats

( Pdf, E-pub, Full Text, Audio)

- Unceasing customer service

Track the below URL for one-step submission https://juniperpublishers.com/online-submission.php 